\title{
Efeito do tratamento de sementes de algodoeiro com fungicidas no controle do tombamento em relação à densidade de inóculo de Rhizoctonia solani.
}

\author{
Augusto César Pereira Goulart
}

Embrapa Agropecuária Oeste - C. P. 661 - CEP: 79804-970 - Dourados, MS, Brasil,

Apoio: Fundect

e-mail: goulart@cpao.embrapa.br

Data de chegada: 08/03/2005. Aceito para publicação em: 18/11/2005.

\begin{abstract}
Goulart, A.C.P. Effect of cotton seed treatments with fungicides to control damping-off in relation to inoculum densities of Rhizoctonia solani. Summa Phytopathologica, v.32, n.4, p.360-366, 2006.

The fungus Rhizoctonia solani Kuhn is considered the most important cause of cotton damping-off in Brazil. Treatment of seeds with fungicides is the most efficient and economical procedure to control this disease. The performance of fungicides depends, among many other factors, of the pathogen population in the soil. This work was carried out, under greenhouse conditions at Embrapa Agropecuária Oeste, Dourados, MS, with the goal to determine the effect of treatment of cotton seeds with fungicides to control damping-off at different inoculum densities of $R$. solani in the soil. Seeds of cultivar DeltaOpal treated or not with different fungicides were sowed $3 \mathrm{~cm}$ deep in sand contained in plastic flats. Seeds were placed in individual and equidistant wells. Inoculum of the fungus was homogeneously distributed in the substrate. The fungus was grown for 35 days on autoclaved oat seeds and then ground to powder using a

mill until reach the size of $1 \mathrm{~mm}$. Four inoculum densities were tested: 1 $\mathrm{g} ; 2 \mathrm{~g} ; 3 \mathrm{~g}$ e $4 \mathrm{~g} /$ plastic flat with dimensions of $56 \times 35 \times 10 \mathrm{~cm}$. The effect of the fungicide treatment on initial and final seedling emergence, as well as, in the control of post and pre-emergence damping-off was observed. Treatment of seed with a combinations of fungicides gave the best results in controlling damping-off as compared to the use of each fungicide alone. The interaction fungicides $\mathrm{x}$ inoculum densities, was significant indicating that the efficiency of the fungicides was somehow affected by the fungus densities. Fungicides had the best performance at low inoculum densities ( $1 \mathrm{~g}$ and $2 \mathrm{~g} / \mathrm{flat}$ ). As for fungi populations of $3 \mathrm{~g}$ and $4 \mathrm{~g} /$ flat, the efficiency of all fungicides tested decreased sharply, with a reduced control of the disease. The fungicides used in this study did not have any phytotoxic effect on cotton seedlings.
\end{abstract}

Additional keywords: soilborne pathogen, fungus density, Gossypium hirsutum.

RESUMO

Goulart, A.C.P. Efeito do tratamento de sementes de algodoeiro com fungicidas no controle do tombamento em relação à densidade de inóculo de Rhizoctonia solani. Summa Phytopathologica, v.32, n.4, p.360-366, 2006.

O fungo Rhizoctonia solani Kuhn é considerado o principal agente causal do tombamento de plântulas do algodoeiro no Brasil. A maneira mais eficiente e econômica de controlar essa doença é através do tratamento das sementes com fungicidas. A performance dos fungicidas depende, dentre outros fatores, da população desse fungo no solo. Este trabalho foi desenvolvido, em condições de casa de vegetação, na Embrapa Agropecuária Oeste, em Dourados, MS, com o objetivo de determinar o efeito do tratamento de sementes de algodoeiro com fungicidas, no controle do tombamento, em relação a diferentes densidades de inóculo de $R$. solani no solo. Sementes da cultivar DeltaOpal, tratadas e não tratadas com diferentes fungicidas, foram semeadas a $3 \mathrm{~cm}$ de profundidade em areia contida em bandejas plásticas. As sementes foram dispostas em orifícios individuais e eqüidistantes. A inoculação com o fungo foi feita pela distribuição homogênea do inóculo na superfície do substrato. O fungo foi cultivado por 35 dias em sementes de aveia preta autoclavadas e trituradas em moinho $(1 \mathrm{~mm})$. Quatro densidades de inóculo foram testadas: $1 \mathrm{~g} ; 2 \mathrm{~g} ; 3 \mathrm{~g}$ e $4 \mathrm{~g} / \mathrm{b}$ andeja plástica de $56 \times 35 \times 10 \mathrm{~cm}$. Foi observado efeito do tratamento fungicida na emergência inicial e final de plântulas, bem como no controle do tombamento de pré e pós-emergência. $\mathrm{O}$ tratamento das sementes com a mistura de fungicidas proporcionou os melhores resultados no controle do tombamento em comparação ao seu uso isolado. A interação fungicidas $\mathrm{x}$ densidade de inóculo foi significativa, indicando que a eficiência dos fungicidas foi influenciada pela densidade de inóculo do fungo. A performance dos fungicidas testados foi melhor na presença dos níveis mais baixos de inóculo do fungo $(1,0 \mathrm{~g}$ e 2,0 g/ bandeja). A eficiência dos fungicidas testados foi menor para as populações de $3,0 \mathrm{~g}$ e 4,0g do patógeno, sendo que a maioria dos tratamentos fungicidas apresentou perda significativa de eficiência na presença desses níveis de $R$. solani. Os fungicidas usados neste estudo não apresentaram efeitos fitotóxicos às plântulas de algodoeiro.

Palavras-chave adicionais:patógeno de solo, densidade de inóculo, Gossypium hirsutum. 
De todas as doenças que atacam o algodoeiro (Gossypium hirsutum L.), o "tombamento" é considerado uma das principais $(2,8,9,14$, 21). Vários fungos podem causar o "tombamento" de plântulas de algodoeiro, porém Rhizoctonia solani Kuhn., é considerado o principal agente etiológico dessa doença, seguido de Fusarium spp. e Pythium sp., que são considerados secundários, nas condições do Brasil, conforme Santos et al. (17), Tanaka et al. (19) e Tanaka \& Menten (20).

No Brasil, principalmente em se tratando do algodoeiro do cerrado, o principal agente causal do tombamento de plântulas é $R$. solani grupo de anastomose (AG)-4 (teleomorfo: Thanatephorus cucumeris (A.B. Frank) Donk), devido à frequiência que ocorre (mais de $95 \%$ dos casos) e pelos danos que causa na fase inicial de estabelecimento da lavoura (9).

Este fungo ataca as sementes e plântulas de algodoeiro, causando o tombamento de pré e pós emergência (16), sendo considerado por Sinclair (18) o mais prejudicial que os demais por provocar, em maior intensidade, o tombamento de pré-emergência.

Dentre as práticas recomendadas para o controle do tombamento, o tratamento das sementes com fungicidas tem sido, até o momento, a principal medida adotada e a opção mais econômica para minimizar os efeitos negativos dessa doença, conforme evidenciam Davis et al. (2), Garber et al. (5), Goulart \& Melo Filho (8) e Wang \& Davis (21). Trata-se de prática indispensável quando se reduz a quantidade de sementes na semeadura, visando eliminar a operação de desbaste, tornando-se cada vez mais difundida e adotada em esquemas de controle integrado de doenças do algodoeiro (9).

A cada ano, um grande número de fungicidas são avaliados com o objetivo de verificar sua eficiência no controle do tombamento. De acordo com Davis et al. (2), Garber et al. (5), Goulart (10, 12) e Wang \& Davis (21), a performance desses produtos é influenciada pela pressão de inóculo do patógeno no solo e também pelas interações com outros fungos, o que pode evidenciar um controle biológico. Igualmente, a suscetibilidade das cultivares também poderá influenciar nos benefícios do tratamento de sementes com fungicidas. Esses mesmos autores evidenciam ainda que os benefícios do tratamento de sementes de algodoeiro com fungicidas são menos evidentes em áreas onde a densidade de inóculo do patógeno é relativamente baixa ou quando as condições de umidade e temperatura do solo são ideais a uma rápida germinação e emergência. Entretanto, deve-se considerar que, até o momento, não se tem evidências de que o uso de fungicidas em tratamento de sementes com ação específica contra $R$. solani possa ser dispensado em áreas com histórico de ocorrência deste patógeno.

Trabalhos desenvolvidos por Goulart (6), Goulart et al. (7), Goulart (11) e Goulart (13) no Brasil e Garber et al. (4, 5), Wang \& Davis (21), DeVay et al. (3) e Minton et al. (15) nos EUA evidenciaram que a ação combinada de fungicidas sistêmicos com protetores tem sido uma estratégia das mais eficazes no controle do tombamento de plântulas, causado por $R$. solani, uma vez que o espectro de ação da mistura é ampliado pela ação de dois ou mais produtos. Desse modo, verificam-se melhores emergências de plântulas no campo e melhores índices de controle do tombamento com a utilização de misturas, em comparação ao uso isolado de um determinado fungicida.

Conforme DeVay et al. (3), estudos em casa de vegetação, visando determinar a performance de fungicidas aplicados em tratamento de sementes de algodoeiro, tem sido um indicador bastante útil para predizer a eficácia desses produtos ao nível de campo. Diversos autores têm desenvolvido trabalhos dessa natureza em casa de vegetação, como, por exemplo, Asmus et al. (1), Goulart et al. (7), Goulart (10,
$11,12,13)$, utilizando metodologia de inoculação de $R$. solani no substrato (sementes de aveia preta inoculada com $R$. solani), além de Wang \& Davis (21), que trabalharam com uma mistura de areia:turfa inoculada com $R$. solani e Menten \& Paradela (14), que utilizaram solo inoculado com $R$. solani, através da distribuição de sementes de trigo autoclavadas e colonizadas pelo fungo.

O objetivo deste trabalho foi avaliar o efeito do tratamento de sementes de algodoeiro com fungicidas no controle do tombamento em relação à densidade de inóculo de $R$. solani.

\section{MATERIAL E MÉTODOS}

O ensaio foi conduzido na casa de vegetação da Embrapa Agropecuária Oeste, em Dourados, MS, com sementes de algodoeiro, cv. DeltaOpal, deslintadas com ácido sulfúrico. O experimento foi instalado no mesmo dia em que as sementes foram tratadas com os fungicidas (Tabela 1).

Foi utilizado o delineamento experimental em esquema fatorial, inteiramente casualizado, com 19 tratamentos e quatro repetições de 200 sementes cada. Para a análise de variância, os dados de percentagem foram transformados para arc sen $\sqrt{x / 100}$. As médias foram comparadas pelo teste de Duncan, ao nível de 5\% de probabilidade.

\section{Produção do inóculo de $R$. solani}

Culturas puras de $R$. solani AG-4, isolado de lesões do coleto de plântulas de algodoeiro, foram mantidas em meio de cultura BDA por 48 horas, tempo necessário para o crescimento do patógeno. Após esse período, o fungo foi repicado para um substrato composto de 2 $\mathrm{kg}$ de sementes de aveia preta e $0,5 \mathrm{~L}$ de água, previamente autoclavado, em Erlenmeyer de 2,0 L, durante 30 minutos, por três dias consecutivos, a $127^{\circ} \mathrm{C}(1,5 \mathrm{~atm}$ de pressão) sendo mantido em condições ambientes por 35 dias. No $35^{\circ}$ dia, retirou-se do Erlenmeyer a aveia colonizada pelo fungo, a qual foi seca à sombra por dez dias. Ao final desse período, esse substrato (aveia $+R$. solani) foi triturado em um moinho ( $1 \mathrm{~mm})$, de modo a se obter o inóculo do patógeno, na forma de um pó.

\section{Semeadura e inoculação com $R$. solani}

Sementes tratadas e não tratadas com os fungicidas foram semeadas em bandejas plásticas $(56 \times 35 \times 10 \mathrm{~cm})$ contendo areia lavada, previamente autoclavada por três vezes consecutivas, sendo cada uma por 3 horas a $127^{\circ} \mathrm{C}$ e $1,5 \mathrm{~atm}$ de pressão. As sementes foram distribuídas em orifícios individuais, eqüidistantes e a $3 \mathrm{~cm}$ de profundidade. Antes do fechamento dos orifícios, foi feita a inoculação com $R$. solani, pela distribuição homogênea do inóculo do fungo na superfície do substrato, de modo que o mesmo ficasse em contato direto com as sementes. Foram definidas quatro densidades populacionais ( $1 \mathrm{~g} ; 2 \mathrm{~g} ; 3 \mathrm{~g}$; e $4 \mathrm{~g}$ do inóculo do fungo/bandeja) do fungo, com base na patogenicidade do inóculo inicial de $R$. solani, níveis estes ajustados em função da percentagem de tombamento observado, conforme metodologia proposta por Wang \& Davis (21) e Weinhold (22). Para comparação, foram deixadas duas testemunhas, uma inoculada com o fungo $R$. solani e outra não inoculada.

\section{Avaliações}

Para as avaliações de emergência e de tombamento de pré e pósemergência, utilizou-se o "growing on test". Para cada bandeja plástica contendo areia lavada, foram semeadas 200 sementes. Foram realizadas duas avaliações de emergência: a avaliação inicial (aos sete dias após a 
Tabela 1: Fungicidas (nome comercial e nome técnico) e doses (produto comercial e ingrediente ativo) utilizados no ensaio.

\begin{tabular}{cccc}
\hline & Fungicidas & \multicolumn{2}{c}{ Dose (g ou ml/100kg de sementes) } \\
\hline Nome Comercial & Nome Técnico & P.C. ${ }^{\mathbf{2}}$ & i.a. $^{{ }^{2}}$ \\
\hline Euparen & tolylfluanid & 150 & 75 \\
Baytan & triadimenol & 200 & 30 \\
Monceren & pencycuron & 300 & 75 \\
Euparen+Monceren+Baytan & tolylfluanid+ pencycuron+triadimenol & $200+300+200$ & $100+75+30$ \\
Premis & triticonazole & 300 & 60 \\
Rhodiauram & thiram & 400 & 200 \\
Premis+ Rhodiauram & triticonazole+thiram & $300+400$ & $60+200$ \\
Kobutol & PCNB & 500 & 375 \\
Euparen+Monceren+Baytan & tolylfluanid+pencycuron+triadimenol & $150+200+200$ & $30+50+50$ \\
+Kobutol & +PCNB & +500 & +375 \\
Vitavax-thiram & carboxin+thiram & 700 & $187,5+187,5$ \\
Vitavax-thiram+Kobutol & carboxin+thiram+PCNB & $700+500$ & $187,5+187,5+375$ \\
Frowncide & fluazinam & 300 & 150 \\
Sumilex & procimidone & 300 & 150 \\
Cercobin & tiofanato metílico & 300 & 150 \\
Frowncide+Cercobin & fluazinam+tiofanato metílico & $300+300$ & $150+150$ \\
Sumilex+Cercobin & procimidone+ tiofanato metílico & $300+300$ & $150+150$ \\
\hline
\end{tabular}

${ }^{1}$ P.C.=produto comercial

${ }^{2}$ i.a.=ingrediente ativo

semeadura - 7 DAS) e a avaliação final (aos 26 DAS). A avaliação de tombamento foi realizada diariamente, a partir dos 7 DAS, computandose o número de plântulas tombadas até os 26 DAS. Ao final desse período, obteve-se um valor final cumulativo de plântulas tombadas. Para a confirmação do patógeno, plântulas com sintomas de "tombamento" foram coletadas, lavadas em água corrente, desinfestadas superficialmente com uma solução de hipoclorito de sódio a $1,5 \%$ por três minutos e posteriormente submetidas a uma "câmara úmida". Após cinco dias de incubação a $22^{\circ} \mathrm{C}$ e $12 \mathrm{~h}$ luz/12h escuro, foi realizada a leitura e identificação do patógeno.

Para garantir que os resultados revelassem única e exclusivamente o efeito do fungo $R$. solani sobre a emergência e tombamento, foi utilizado um lote de sementes livre de qualquer espécie de fungo, escolha baseada em resultados de vários testes de sanidade de sementes, que pudesse interferir nas avaliações. O tratamento fungicida, quando necessário, foi realizado colocando-se os produtos sobre $500 \mathrm{~g}$ de sementes em sacos plásticos de 2,0 L e agitando-se o recipiente por alguns minutos, até a completa cobertura das sementes pelos fungicidas.

\section{RESULTADOS E DISCUSSÃO}

A análise de variância mostrou efeito significativo do tratamento fungicida na emergência inicial e final de plântulas, bem como no controle do tombamento de pré e pós-emergência do algodoeiro (Tabelas 2, 3, 4 e 5) com os melhores resultados sendo obtidos pelos tratamentos tolylfluanid + pencycuron + triadimenol, tolylfluanid + pencycuron + triadimenol + PCNB, fluazinam + tiofanato metílico, seguidos de carboxin + thiram + PCNB. Os demais fungicidas testados foram significativamente inferiores, proporcionando menores percentagens de plântulas emergidas e níveis mais baixos de controle do tombamento de plântulas de algodoeiro, em comparação a estes tratamentos mais eficientes. Foi observado efeito significativo da interação entre fungicidas e densidade populacional de $R$. solani
(Tabelas 2, 3, 4 e 5), com as populações do patógeno influenciando significativamente a eficiência do tratamento de sementes. A performance dos fungicidas foi melhor na presença dos níveis mais baixos de inóculo do fungo ( $1,0 \mathrm{~g} \mathrm{e} 2,0 \mathrm{~g} / \mathrm{bandeja)} \mathrm{em} \mathrm{comparação} \mathrm{com}$ os resultados obtidos para as populações de 3,0 g e 4,0 g, com destaque para tolylfluanid + pencycuron + triadimenol, , tolylfluanid + pencycuron + triadimenol + PCNB, fluazinam + tiofanato metílico, seguidos de carboxin + thiram + PCNB. A maioria dos tratamentos fungicidas apresentou perda significativa de eficiência na presença dos níveis mais altos do patógeno. Os resultados mostraram claramente uma redução da emergência inicial e final com o aumento da população de $R$. solani. Por outro lado, com relação ao tombamento de pré e de pós-emergência, incrementos nesses parâmetros foram observados com o aumento do nível de inóculo de $R$. solani.

O fungo $R$. solani pode causar tombamento de pré e pósemergência, o que foi observado nas condições do presente ensaio. A avaliação da percentagem de emergência final de plântulas (26 DAS), reflete a eficiência dos fungicidas na proteção das mesmas contra o ataque de $R$. solani, bem como a capacidade de manutenção do estande, no sentido de evitar o tombamento de pós-emergência causado por este patógeno. $\mathrm{O}$ efeito drástico do patógeno pode ser claramente observado quando se comparam os resultados obtidos nas testemunhas com e sem inoculação. As diferenças estatísticas entre os tratamentos fungicidas e a testemunha inoculada refletem e demonstram a boa eficiência de alguns dos produtos testados nesse ensaio na manutenção da emergência de plântulas e no controle do tombamento causado por R. solani.

Asmus et al. (1) e Goulart et al. (7), utilizaram esta mesma metodologia de inoculação de $R$. solani, além de Menten \& Paradela (14) e Wang \& Davis (21) e chegaram a resultados semelhantes, os quais observaram aumento na emergência e controle do tombamento de plântulas causado por $R$. solani, quando as sementes de algodoeiro foram tratadas com fungicidas. Os resultados obtidos neste ensaio 
Tabela 2. Emergência inicial de plântulas de algodoeiro (\%) em função do tratamento fungicida e dos níveis de inóculo de Rhizoctonia solani.

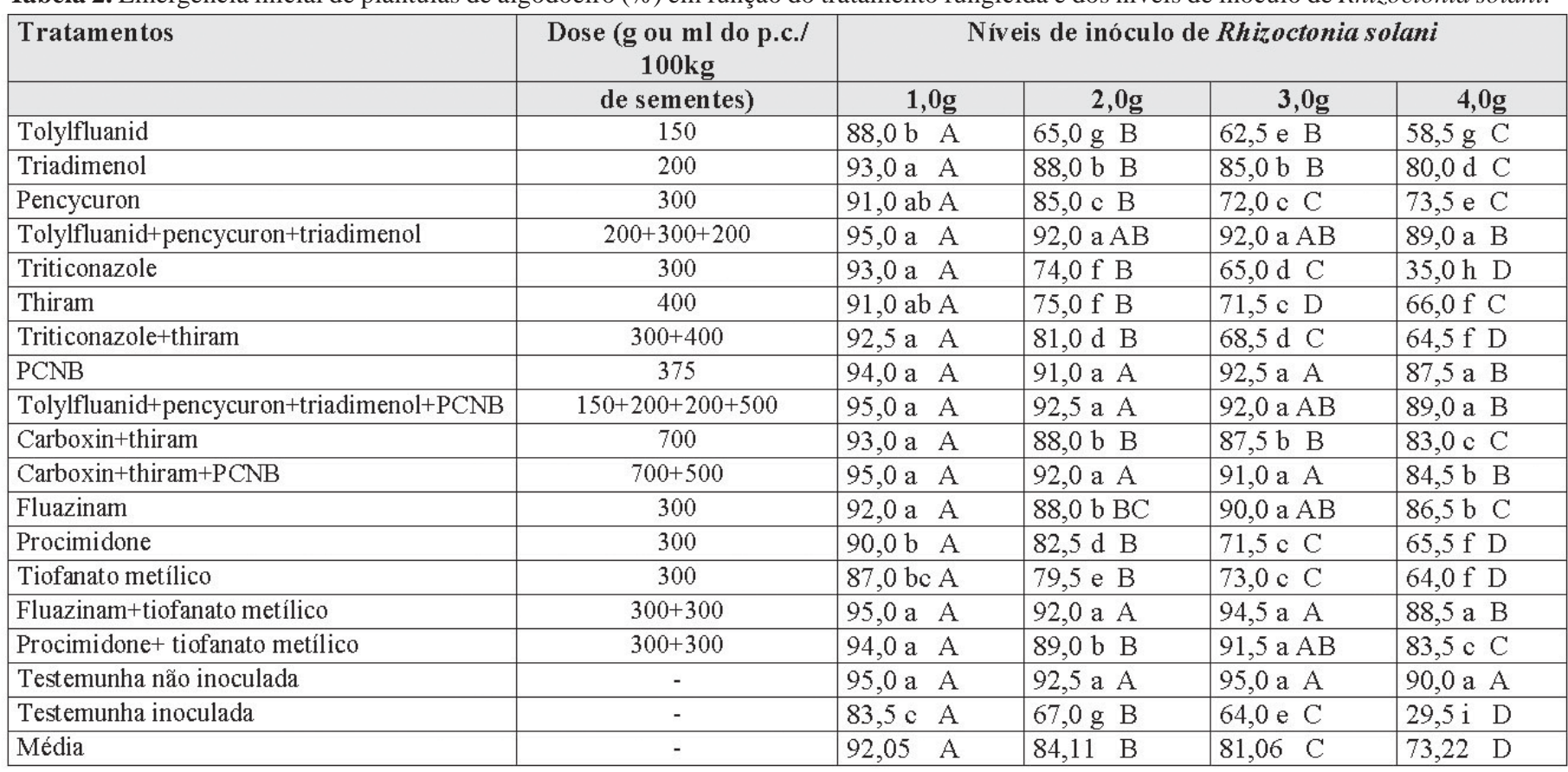

Médias seguidas pela mesma letra minúscula nas colunas e maiúscula nas linhas não diferem significativamente entre si (Duncan, 5\%)

C.V. $(\%)=8,31$

Tabela 3. Emergência final de plântulas de algodoeiro (\%) em função do tratamento fungicida e dos níveis de inóculo de Rhizoctonia solani.

\begin{tabular}{|c|c|c|c|c|c|}
\hline Tratamentos & $\begin{array}{c}\text { Dose (g ou ml do p.c./ } \\
100 \mathrm{~kg}\end{array}$ & & is de inócul & Rhizoctoni & lani \\
\hline & de sementes) & $1,0 \mathrm{~g}$ & $2,0 \mathrm{~g}$ & $3,0 \mathrm{~g}$ & $4,0 \mathrm{~g}$ \\
\hline Tolylfluanid & 150 & 74,0 e $\mathrm{A}$ & $48,0 \mathrm{~g} \mathrm{~B}$ & 40,0 g. C & $35,0 \mathrm{~h} \mathrm{D}$ \\
\hline Pencycuron & 300 & $91,0 \mathrm{~b} \mathrm{~A}$ & 80,0 c B & $66,0 \mathrm{~d} \mathrm{C}$ & 65,5 e $C$ \\
\hline Tolylfluanid + pencycuron+triadimenol & $200+300+200$ & 95,0 a $\mathrm{A}$ & 92,0 a B & 91,0 a BC & 89,0 a C \\
\hline Triticonazole & 300 & 89,5 b A & $70,0 \mathrm{~d} \mathrm{~B}$ & 47,0 f. C & $31,0 \mathrm{i} \quad \mathrm{D}$ \\
\hline Triticonazole+thiram & $300+400$ & 89,5 b A & 79,0 c B & 60,0 e $C$ & $55,0 \mathrm{f} \mathrm{D}$ \\
\hline PCNB & 375 & 94,0 a $\mathrm{A}$ & 87,0 b B & $80,0 \mathrm{c} \mathrm{C}$ & $72,0 \mathrm{~d}$ D \\
\hline Tolylfluanid + pencycuron + triadimenol $+\mathrm{PCNB}$ & $150+200+200+500$ & 95,0 a $\mathrm{A}$ & 92,0 a $\mathrm{A}$ & 92,0 a $A B$ & 89,0 a B \\
\hline Carboxin+thiram & 700 & $90,0 \mathrm{~b} \mathrm{~A}$ & 81,5 c B & $79,0 \mathrm{c} \mathrm{B}$ & $70,0 \mathrm{~d} \mathrm{C}$ \\
\hline Carboxin+thiram+PCNB & $700+500$ & 95,0 a $\mathrm{A}$ & 92,0 a $\mathrm{A}$ & $85,0 \mathrm{~b} \quad \mathrm{~B}$ & $77,0 \mathrm{c} \mathrm{C}$ \\
\hline Fluazinam & 300 & $85,0 \mathrm{c} \mathrm{A}$ & 77,0 c B & $71,5 \mathrm{~d} \quad \mathrm{C}$ & $47,0 \mathrm{~g} \quad \mathrm{D}$ \\
\hline Procimidone + tiofanato metílico & $300+300$ & $88,0 \mathrm{~b} \mathrm{~A}$ & $78,0 \mathrm{c} \mathrm{B}$ & $79,5 \mathrm{c} \quad \mathrm{B}$ & $70,0 \mathrm{~d} \mathrm{C}$ \\
\hline Testemunha não inoculada & - & 95,0 a $\mathrm{A}$ & 92,5 a $\mathrm{A}$ & $95,0 \mathrm{a} \quad \mathrm{A}$ & 90,0 a $\mathrm{A}$ \\
\hline Testemunha inoculada & - & $65,5 \mathrm{f} \mathrm{A}$ & $38,0 \mathrm{~h} \mathrm{~B}$ & $31,0 \mathrm{~h} \mathrm{C}$ & $9,5 \mathrm{j} \quad \mathrm{D}$ \\
\hline Média & - & $88,11 \mathrm{~A}$ & $76,47 \quad \mathrm{~B}$ & $69,92 \quad \mathrm{C}$ & $60,83 \quad \mathrm{D}$ \\
\hline
\end{tabular}

Médias seguidas pela mesma letra minúscula nas colunas e maiúscula nas linhas não diferem significativamente entre si (Duncan, 5\%)

C.V. $(\%)=9,25$

demonstraram, de maneira geral, melhores emergências de plântulas e menor percentagem de tombamento de pós-emergência com a utilização de misturas de fungicidas, em comparação ao uso isolado de um determinado produto, concordando com aqueles encontrados por Davis et al. (2), Goulart (6), Goulart et al. (7), Menten \& Paradela (14) e Wang \& Davis (21). Deve-se ressaltar que a ação combinada de fungicidas com diferentes espectros de ação tem sido uma estratégia eficaz no controle de maior número de patógenos presentes nas sementes e/ou no solo, além de evitar, em grande parte, o surgimento de populações resistentes entre os patógenos. Desse modo, a utilização de misturas de fungicidas, garante aos produtores maior segurança na semeadura para a obtenção de um estande ideal de plantas, nas mais 
Tabela 4. Tombamento de pré-emergência de plântulas de algodoeiro (\%) em função do tratamento fungicida e dos níveis de inóculo de Rhizoctonia solani.

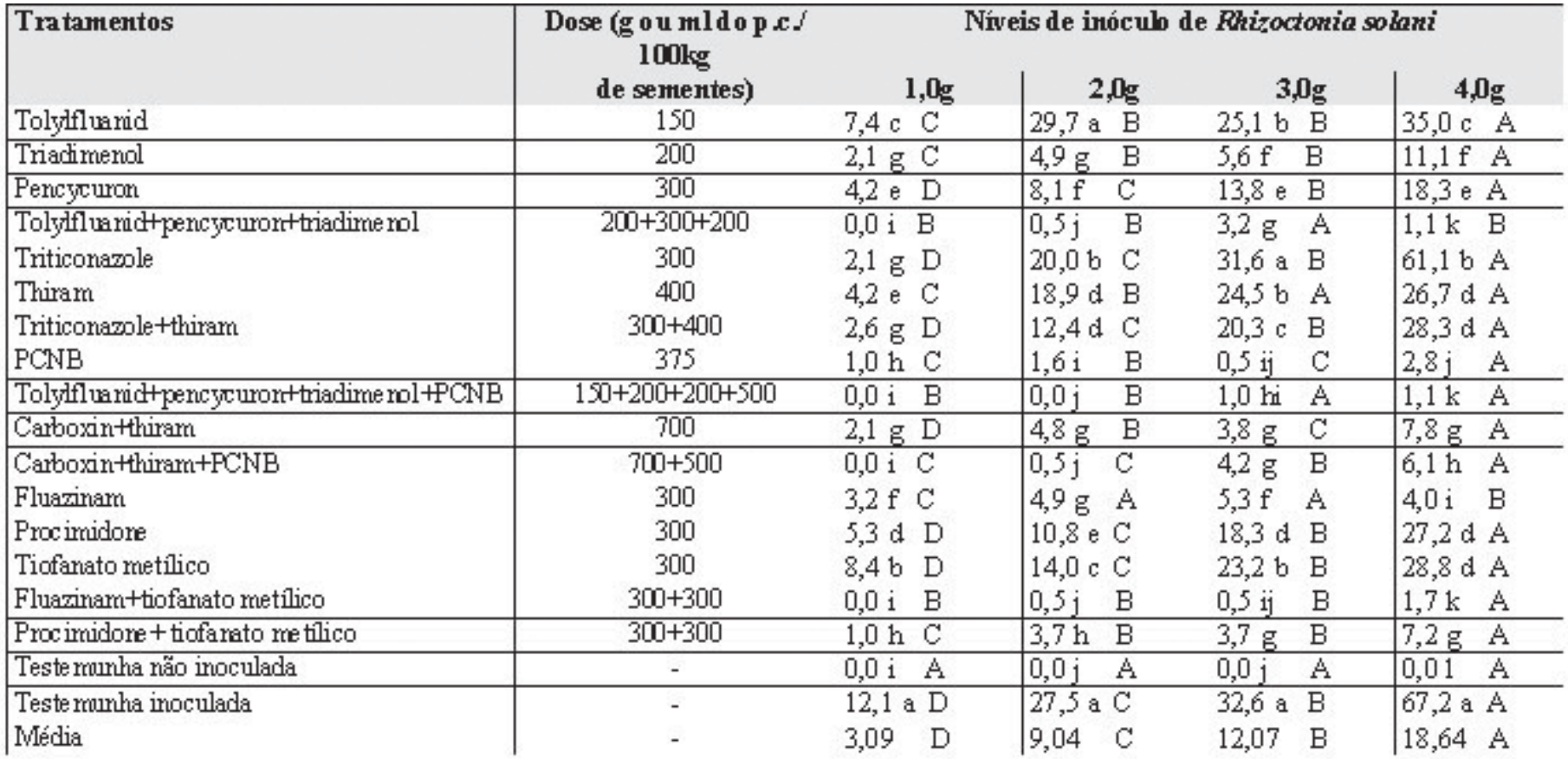

Médias seguidas pela mesma letra minúscula nas colunas e maiúscula nas linhas não diferem significativamente entre si (Duncan, 5\%)

C.V. $(\%)=12,38$

Tabela 5. Tombamento de pós-emergência de plântulas de algodoeiro (\%) em função do tratamento fungicida e dos níveis de inóculo de Rhizoctonia solani.

\begin{tabular}{|c|c|c|c|c|c|}
\hline Tratamentos & $\begin{array}{c}\text { Do se (g ou mldo p c } / \\
\text { lookg } \\
\text { de sementes) }\end{array}$ & \multicolumn{4}{|c|}{ Niveis de inóculo de Rhżoctonia solmi } \\
\hline Tolyflluarid & 150 & $15,4 \mathrm{~b} D$ & $26,1 \mathrm{c} \mathrm{C}$ & 36,0 с B & $40,2 \mathrm{dA}$ \\
\hline Pencycuron & 300 & $0,0 \mathrm{~h}$ & $5,8 \mathrm{~g} \mathrm{~B}$ & $10,5 \mathrm{~h} \mathrm{~A}$ & $11,0 \mathrm{~h} \mathrm{~A}$ \\
\hline Tolyifluarid+pencycuronttriadimenol & $200+300+200$ & $0,0 \mathrm{~h}$ & $0,0 \mathrm{k}$ A & $1,01 \mathrm{~A}$ & $0,0 \mathrm{k} \quad \mathrm{A}$ \\
\hline Triticonazole & 300 & $5,4 \mathrm{e}$ & $5,4 \mathrm{~g} \quad \mathrm{C}$ & $27,7 \mathrm{dA}$ & $11,4 \mathrm{~h} \mathrm{~B}$ \\
\hline Triticonazole+thiram & $300+400$ & $3,2 \mathrm{~g}$ & $2,5 \mathrm{j} \mathrm{C}$ & $12,4 \mathrm{~g} \mathrm{~B}$ & $14,7 \mathrm{~g} \mathrm{~A}$ \\
\hline PCNB & 375 & $0,0 \mathrm{~h}$ & $4,4 \mathrm{~h} \mathrm{C}$ & $13,5 \mathrm{~g} \mathrm{~B}$ & $17,7 \mathrm{f} \mathrm{A}$ \\
\hline Tolyffluarid+pencycuron+triadimenol+PCNB & $150+200+200+500$ & $0,0 \mathrm{~h} \quad \mathrm{~A}$ & $0,0 \mathrm{k}$ A & $0,0 \mathrm{n} \quad \mathrm{A}$ & $0,0 \mathrm{k} \mathrm{A}$ \\
\hline Carboxintthiram & 700 & $3,2 \mathrm{~g}$ & $7,3 \mathrm{f} \quad \mathrm{C}$ & $9,7 \mathrm{~h} \quad \mathrm{~B}$ & $15,6 \mathrm{~g} \mathrm{~A}$ \\
\hline Carboxintthiram $+\mathrm{PCNB}$ & $700+500$ & $0,0 \mathrm{~h}$ & $0,0 \mathrm{k} \quad \mathrm{C}$ & $6,6 \mathrm{j} \quad \mathrm{B}$ & $8,9 \mathrm{~h} \quad \mathrm{~A}$ \\
\hline Fluazinam & 300 & $7,6 \mathrm{c} \quad \mathrm{D}$ & 12,5 e $\mathrm{C}$ & 20,6 e $B$ & $45,7 \mathrm{c} \mathrm{A}$ \\
\hline Procimidone+tiofanato metilico & $300+300$ & $6,4 \mathrm{~d}$ & 12,3 e $A$ & $13,1 \mathrm{~g} A$ & $10,8 \mathrm{~h} \mathrm{~B}$ \\
\hline Teste mumha não inoculada & - & $0,0 \mathrm{~h} \quad \mathrm{~A}$ & $0,0 \mathrm{k} \quad \mathrm{A}$ & $0,0 \mathrm{n} \quad \mathrm{A}$ & $0,0 \mathrm{k} A$ \\
\hline Teste mumha inoculada & - & 21,6 a D & 43,3 a $\mathrm{C}$ & 51,6 a B & 67,8 a $\mathrm{A}$ \\
\hline Média & - & $4,54 \quad \mathrm{D}$ & $10,01 \mathrm{C}$ & $15,34 \quad \mathrm{~B}$ & $19,31 \quad A$ \\
\hline
\end{tabular}

Médias seguidas pela mesma letra minúscula nas colunas e maiúscula nas linhas não diferem significativamente entre si (Duncan, 5\%)

C.V. $(\%)=11,88$

variadas situações.

Conforme DeVay et al. (3), Goulart et al. (7) e Goulart (10, 11, 12,13 ), estudos em casa de vegetação, para determinar a performance de fungicidas aplicados em tratamento de sementes de algodoeiro, têm sido um indicador bastante útil para predizer a eficácia desses produtos oa nível de campo. Diversos autores têm desenvolvido trabalhos dessa natureza em casa de vegetação, como, por exemplo, Asmus et al. (1) e Goulart et al. (7), que utilizaram esta mesma metodologia de inoculação de $R$. solani, além de Wang \& Davis (21), que trabalharam com uma mistura de areia e turfa inoculada com $R$. solani e Menten \& Paradela 
(14), que utilizaram solo inoculado $\operatorname{com} R$. solani, através da distribuição de sementes de trigo autoclavadas e colonizadas pelo fungo.

Os resultados deste trabalho, somados àqueles citados anteriormente, demonstram a exequibilidade desse método de inoculação do substrato com $R$. solani, para avaliar a eficiência do tratamento de sementes de algodoeiro com fungicidas no controle desse patógeno, em condições de casa de vegetação. Esse tipo de trabalho proporciona resultados altamente confiáveis, uma vez que se trabalha em condições controladas, com quantidades e pressões de inóculo preestabelecidos, que permitem avaliar com precisão e praticamente sem chances de escape, os benefícios do tratamento de sementes com fungicidas, em função de diferentes populações de um determinado patógeno.

Nos EUA, vários estudos envolvendo benefícios do tratamento de sementes de algodoeiro com fungicidas, em relação ao potencial de inóculo de $R$. solani no solo, têm sido realizados (2, 4, 5, 21). No Brasil, até o momento, poucos trabalhos dessa natureza foram realizados, como, por exemplo, aqueles desenvolvidos por Goulart $(10,12)$.

Os resultados obtidos demonstraram claramente a necessidade do uso do tratamento de sementes com fungicidas, além de mostrar que a eficiência de um determinado produto está diretamente relacionada com a população de $R$. solani no solo, o que está de acordo com resultados obtidos por Garber et al. $(4,5)$ e Davis et al. (2). Observou-se ainda melhor eficiência dos fungicidas frente às populações mais baixas do fungo no solo e que, na presença de maiores níveis de inóculo do patógeno, a eficácia dos mesmos reduz significativamente. Estes resultados corroboram aqueles obtidos por Moustafa-Mahmoud et al. (16), os quais evidenciaram ainda que o tratamento de sementes de algodoeiro com fungicidas pode não proporcionar controle adequado do tombamento em solos frios, úmidos e com histórico severo de tombamento. Segundo Davis et al. (2), os benefícios do tratamento de sementes de algodoeiro com fungicidas são menos evidentes em áreas onde a densidade de inóculo do patógeno é relativamente baixa ou quando as condições de Umidade e temperatura do solo são idais a uma rápida germinação e emergência. Conforme resultado obtido por Weinhold (22), considera-se como baixa uma população de dois propágulos de $R$. solani/100 g de solo, o que corresponde, em testes de casa de vegetação com infestação artificial do solo com o fungo, $20 \%$ de tombamento na testemunha não inoculada. Entretanto, e deve-se considerar que, até o momento, não se tem evidências de que o uso de fungicidas em tratamento de sementes com ação específica contra $R$. solani possa ser dispensado em áreas com histórico de ocorrência deste patógeno $(2 ; 7,9)$.

O tratamento de sementes de algodoeiro deve ser considerado como uma das alternativas mais eficazes para o controle do tombamento nessa cultura. Trata-se de uma medida de fácil execução, barata pela relação custo/benefício, onerando em apenas $0,17 \%$ o custo total de produção (8), vindo de encontro à necessidade de se racionalizar o uso de produtos químicos na agricultura (9). Julga-se oportuno salientar que, principalmente quando se trata de algodoeiro, cujo nível de tecnologia de produção de sementes no Brasil ainda não é considerado como um dos mais elevados, o tratamento de sementes com fungicidas se faz necessário e até mesmo indispensável.

\section{REFERÊNCIAS BIBLIOGRÁFICAS}

1. Asmus, G.L.; Goulart, A.C.P.; Paiva, F. de A. Eficiência de alguns fungicidas usados em tratamento de sementes de algodão no con- trole do tombamento causado por Rhizoctonia solani. Fitopatologia Brasileira, Brasília, DF, v.18, Supl., p.298, 1993.

2. Davis, R.M.; Nunez, J.J.; Subbarao, K.V. Benefits of cotton seed treatments for the control of seedling diseases in relation to inoculum densities of Pythium species and Rhizoctonia solani. Plant Disease, St. Paul, v.81, n.7, p.766-768, 1997.

3. Devay, J.E.; Garber, R.H.; Wakeman, R.J. Cotton seedling responses in greenhouse tests to combinations of chemical seed treatment for control of Pythium ultimum, Rhizoctonia solani, and Thielaviopsis basicola. In: BELTWIDE COTTON PRODUCTION RESEARCH CONFERENCES, 1980. Proceedings... Memphis: National Cotton Council, 1980. p.19.

4. Garber, R.H.; Devay, J.E.; Weinhold, A.R.; Matheron, D. Relationship of pathogen inoculum to cotton seedling disease control with fungicides. Plant Disease Reporter, Beltsville, v.63, n.3, p.246-250, 1979.

5. Garber, R.H.; Devay, J.E.; Weinhold, A.R.; Wakeman, R.J. Pathogen inoculum a key factor in fungicide seed treatment efficiency. In: BELTWIDE COTTON PRODUCTION RESEARCH CONFERENCES, 1980. Proceedings... Memphis: National Cotton Council, 1980. p.19.

6. Goulart, A.C.P. Controle do tombamento de plântulas do algodoeiro causado por Rhizoctonia solani pelo tratamento de sementes com fungicidas. In: CONGRESSO BRASILEIRO DE ALGODÃO, 2., 1999, Ribeirão Preto. Anais...Campina Grande: CNPA, EMBRAPA, 1999. p. 478-80.

7. Goulart, A.C.P.; Andrade, P.J.M.; Borges, E.P. Controle do tombamento de plântulas do algodoeiro causado por Rhizoctonia solani pelo tratamento de sementes com fungicidas. Summa Phytopathologica, Jaboticabal, v.26, n.3, p.362-368, 2000.

8. Goulart, A.C.P.; Melo Filho, G.A. de. Quanto custa tratar as sementes de soja, milho e algodão com fungicidas? Boletim de Pesquisa. Embrapa Agropecuária Oeste, Dourados, n.7, 2000. 31p.

9. Goulart, A.C.P. Tratamento de sementes do algodoeiro com fungicidas. In: ALGODÃO: tecnologia de produção. Dourados: Embrapa Agropecuária Oeste; Campina Grande: Embrapa Algodão, 2001. p.140-158.

10. Goulart, A.C.P. Benefícios do tratamento de sementes de algodão com fungicidas no controle do tombamento em relação à densidade de inóculo de Rhizoctonia solani. Fitopatologia Brasileira, Brasília, DF, v.27, Supl., p.218, 2002a.

11. Goulart, A.C.P. Efeito do tratamento de sementes de algodão com fungicidas no controle do tombamento de plântulas causado por Rhizoctonia solani. Fitopatologia Brasileira, Brasília, DF, v.27, n.4, p.399-402, 2002 b.

12. Goulart, A.C.P. Influência da densidade de inóculo de Rhizoctonia solani na eficiência do tratamento de sementes de algodão com fungicidas no controle do tombamento. In: CONGRESSO BRASILEIRO DO ALGODÃO, 4., 2003, Goiânia. Algodão: um mercado em evolução: anais. Campina Grande: Embrapa Algodão: Fundação GO, 2003. (Embrapa Algodão. Documentos, 118). CD-ROM.

13. Goulart, A.C.P. Efeito do tratamento de sementes de algodão com fungicidas no controle do tombamento de plântulas causado por Rhizoctonia solani. In: CONGRESSO BRASILEIRO DE FITOPATOLOGIA, 36., 2003, Uberlândia. Manejo integrado de doenças e plantas. Uberlândia: Sociedade Brasileira de Fitopatologia: UFU, 2003b. CD-ROM.

14. Menten, J.O.M.; Paradela, A.L. Tratamento químico de sementes de algodão para controle de Rhizoctonia solani. Summa Phytopathologica, Jaboticabal, v.22, n.1, p.60, 1996. 
15. Minton, E.B.; Garber, R.H.; Bird, L.S.; Devay, J.E.; Evrard, T. Effects of fungicide seed treatments that control specific pathogens on stand and yield of cotton. In: BELTWIDE COTTON PRODUCTION RESEARCH CONFERENCES, 1986, Las Vegas. Proceedings... Memphis: National Cotton Council: The Cotton Foundation, 1986. p.20. Disponível em: <http:/ /www.cotton.org/beltwide/proceedings>. Acesso em: 6 out.2004.

16. Moustafa-Mahmoud, S.M.; Sumner, D.R.; Ragab, M.M.; Ragab, M.M. Interaction of fungicides, herbicides, and planting date with seedling disease of cotton caused by Rhizoctonia solani AG-4. Plant Disease, St. Paul, v.77, n.1, p.79-86, 1993.

17. SANTOS, C.M. dos; ALVARENGA, A. de P.; SILVA, R.F. da; ZAMBOLIM, L. Influência do substrato e do tratamento fungicida na germinação e na incidência de fungos em sementes de algodão (Gossypium hirsutum L.). Revista Brasileira de Sementes, Brasília, DF, v.14, n.2, p.151-154, 1992.
18. Sinclair, J.B. Cotton seedling diseases and their control. Baton Rouge: Louisiana State University, 1965. 35p.

19. Tanaka, M.A.S.; Menten, J.O.M.; Marianno, M.J.A. Inoculação artificial de sementes de algodão com Colletotrichum gossypii var. cephalosporioides e infecção das sementes em função do tempo de exposição ao patógeno. Summa Phytopathologica, Jaguariúna, v.15, n.3/4, p.232-237, 1989.

20. Tanaka, M.A.S.; Menten, J.O.M. Comparação de métodos de inoculação de sementes de algodoeiro com Colletotrichum gossypii var. cephalosporioides e C. gossypii. Summa Phytopathologica, Jaguariúna, v.17, n.3/4, p.218-226, 1991.

21. Wang, H.; Davis, R.M. Susceptibility of selected cotton cultivars to seedling disease pathogens and benefits of chemical seed treatments. Plant Disease, St. Paul, v.18, n.9, p.1085-1088, 1997.

22. Weinhold, A.R. Population of Rhizoctonia solani in agricultural soils determined by a screening procedure. Phytopathology, St. Paul, v.67, p.566-569, 1977. 